incidence of clinical cancer are available, but once more problems of educating the public present themselves. Screening programmes on a national scale to detect early or preclinical cancer are fraught with difficulties. Out of a total of some 15 million women in this country between the ages of 15 and 65 fewer than 2 million submitted themselves for cervical smears last year. Further, half of the tests that were carried out were performed on women under the age of 35, though the age of maximum risk is over the age of 35 . The success of screening programmes depends on the facilities available and the efficiency and accuracy of any screening procedures, but of equal importance is the motivation of the patients at risk to come forward for examination.

Cancer of the body of the uterus is becoming more frequent. Why is this? It is a disease of older women, and women are living longer. But this is not the only factor. There is a relationship between this disease and obesity and diabetes, both of which are also increasing in an affluent society. The exact relationship between this disease and oestrogens is not fully understood, but that there is such a relationship seems highly probable. Future research may show the part which progestogens may play, not only in the treatment of benign hyperplasia but by its successful treatment they may have a role in the future prevention of malignant change. We therefore have a situation in which improvement in the standards of living and better education may be reducing the incidence of one disease while causing an increase in the incidence of another.

\section{Conclusion}

The whole of our medical service has been geared towards curative medicine, and the whole of medical education is designed to produce a doctor more capable of treating disease than in preventing it. Our profession is frequently criticized for this attitude. But does not the relative indifference of the public to preventive measures reflect the same attitude, and is it not true that it is vastly easier to obtain finance whether from public or private sources to develop treatment and research rather than to publicize methods of prevention? Cancer research is oversubscribed, cancer education almost entirely unfunded. The efforts required by both educator and the person to be educated in order to promote health needs are not easily obtained. To do something or not to do something in order to prevent the development of a disease or a disorder in the future requires the sort of motivation that few people have instinctively and a great many actively resist. When the Royal College of Physicians recently published its second report on the harmful effects to health of smoking cigarettes, there appeared a leading article in at least one newspaper denouncing the arrogant doctors for daring to tell the public how they should order their lives. Unless there is a radical change of attitude on the part of both the profession and the public in this area, progress towards a healthier population must remain inevitably slow.

\section{References}

Baird, D., Hytten, F. E., and Thomson, A. M. (1958). Fournal of Obstetrics and Gynaecology of the British Commonwealth, 65, 865.

Baird, D. (1965). Fournal of Obstetrics and Gynaecology of the British Commonwealth, 72, 139 .

Cartwright, A. (1970). Parents and Family Planning Services, p. 216. London, Routledge and Kegan Paul.

Kottmeier, Hans (1967). Annual Report on Treatment of Carcinoma of Uterus and Vagina, p. 390. Stockholm, Kungl Boktryckeriet.

Schofield, M. (1965). The Sexual Behaviour of Young People. London, Longmans Green.

\title{
Clinical Evaluation of a Rosette Inhibition Test in Renal Allotransplantation
}

\author{
A. MUNRO, \\ C. S. OGG \\ M. BEWICK, \\ L. MANUEL, J. S. CAMERON, \\ F. G. ELLIS, \\ M. BOULTON-JONES,
}

British Medical fournal, 1971, 3, 271-275

\section{Summary}

The formation of spontaneous rosettes by peripheral blood or spleen mononuclear cells when incubated with sheep red blood cells has proved a useful way of assessing the potency of immunosuppressive drugs and antilymphocyte sera in vitro. A test employing the inhibition by antilymphocyte globulin (A.L.G.) of spontaneous rosette formation around peripheral blood mononuclear cells is described. This has been used to assess the degree of

\section{Guy's Hospital, London S.E.1}

A. MUNRO, B.SC., Research Technician, Department of Surgery M. BEWICK, F.R.C.S., Senior Lecturer, Department of Surgery L. MANUEL, Technician, Department of Surgery. J. S. CAMERON, M.D., F.R.C.S., Consultant Physician F. G. ELLIS, M.S., F.R.C.S., Consultant Surgeon M. BOULTON-JÖNES, M.B., M.R.C.P., Senior Medical Registrar C. S. OGG, M.D., M.R.C.P., Renal Physician immunosuppression in patients with renal allografts and uraemic patients on regular haemodialysis.

Twenty-three patients with renal allografts had 21 clinically diagnosed episodes of rejection. In none of these rejection episodes was the minimal inhibitory concentration (M.I.C.) of A.L.G. (that necessary to reduce the spontaneous rosette formation of peripheral cells by $75 \%$ ) less than $1 / 50,000$. Nineteen patients had no rejection episodes during 57 patient/months of continuous observation while the M.I.C. was at a greater dilution than $1 / 50,000$. The test has therefore been of great value in suggesting when an individual is capable of rejecting his graft, and allows the dose of immunosuppressive drugs to be adjusted to a minimum in a controlled fashion. It has been of use in diagnosing rejection in the anuric patient, when the distinction between rejection, urinary tract obstruction, and infection is particularly difficult.

Fifteen patients maintained on regular haemodialysis for more than a year had, as judged by this technique, less reactive lymphocytes than normal healthy controls. The degree of immunosuppression was not as great as in the patients on full immunosuppressive regimens. 


\section{Introduction}

The most difficult problem in the management of a transplanted patient is that of the immunosuppressive regimen. If insufficient therapy is used the allograft undergoes rejection, but if excess is used the patient is liable to the severe side effects of the drugs, especially infection and bone marrow depression and bone disease.

A variety of tests have been devised in an effort to reduce the drug dosage to a safe minimum compatible with graft survival. Those useful in determining when rejection is actually taking place include: hyperchloraemic acidosis (Mookerjee, Gault, and Dossetor, 1969); 24-hour urinary osmolarity (Chisholm, Papadimitriou, Kukatilake, and Shackman, 1969); creatinine clearance (Rapoport and Husdan, 1968); Hippuran ${ }^{131}$ I clearance (Kountz, Luab, and Cohn, 1965; Awad, Bennett, and Martin, 1968); graft biopsy (Kincaid-Smith, 1967; Kincaid-Smith, Morris, Saker, Ting, and Marshall, 1968; Millard, Herbertson, and Evans, 1970); ultrasonic renal flow measurements (Sampson, 1969); fibrinogen ${ }^{131}$ I uptake (Salaman, 1970); urinary lymphocyte count (Hume, Magee, and Kauffman, 1963); and thermography (Birsner, Gershon-Cohen, and Gainey, 1971). The disadvantage of these tests is that in effect they can detect only renal damage.

Other tests examine lymphocyte function as a criterion of the cellular immunity responsible for allograft rejection (Russel and Monaco, 1964). These include: lymphocyte transformation (Tennenbaum, St. Pierre, and Cerilli, 1968); leucocyte migration (Smith, et al., 1969); and RNA synthesis (Parker, 1969; Parker, Ellis, Cameron, and Ogg, 1970; Parker and Mowbray, 1971). These tests take 12-24 hours to produce results, during which time irrecoverable renal damage may occur. They do, on the other hand, measure the activity of the lymphocyte and thus may give warning of impending rejection episodes.

Bach and his colleagues first showed in 1968 that the formation of rosettes was a sensitive in-vitro method of assessing the potency of antilymphocyte sera (Bach and Antoine, 1968; Bach, Dardenne, and Antoine, 1968). They showed that under appropriate conditions lymphocytes from the peripheral blood or spleens of mice would become surrounded by adherent sheep (or pig or dog) red cells to form "rosettes." The same cells failed, when incubated with antilymphocyte globulin (A.L.G.), to aggregate the red cells to the same extent. This failure could be correlated with the ability of the A.L.G. to prolong the life of skin grafts in primates (Bach, Dormont, Dardenne, and Balner, 1970; Bach and Dormont, 1971). The rosette test performed with the use of mouse cells from mice immunized with sheep red cells (Bach, Dardenne, and Fournier, 1969a) proved as sensitive for the immunosuppressive activity of cemical immunosuppressive agents such as azathioprine. As an index of immunosuppression the inhibition of spontaneous rosette formation has also been studied in dogs and man with renal allografts treated with A.L.G. (Brain and Gorcion, 1970; Brain, Gordon, and Willetts, 1970; Bach, Dormont, Dardenne, and Balner, 1969b; Salerni et al., 1970).

The mechanism of spontaneous rosette formation is still obscure. It has been suggested that the sheep red blood cells have an antigenic site (or sites) on the plasma membrane which causes them to adhere to the lymphocytes. Biozzi et al. (1966) and Bach et al. (1969a) thought that the lymphocytes involved were those producing antibody with the antibody remaining on the cell membrane. Storb and Weiser (1966) referred to this as immunocytoadherence. Bach and Dormont (1971) put evidence forward that the central cell appeared to be a thymusdependent antigen-sensitive cell. Brain et al. (1970) suggested that the active peripheral lymphocyte produces a substance which remains attached to its surface and by its molecular configuration can at the same time bind to the antigens on the sheep red cell membrane. Immunosuppressive drugs such as azathioprine and prednisone probably inhibit the formation of this substance. The action of A.L.G. would be to "coat" the lymphocytes involved, preventing this adherence.
We have used in man a test based on the inhibition of spontaneous rosette formation by peripheral blood cells of the lymphocyte series. It seemed possible that cells already subjected to immunosuppressive drugs in vivo may be more susceptible to the inhibitory action of an A.L.G. of known standard potency. Their susceptibility could be tested by measuring the concentration of the standard A.L.G. required to inhibit their spontaneous rosette formation when incubated with sheep red cells. This might give an index of how suppressed the cell-mediated immune responses of the donor of the lymphocytes might be, and hence whether rejection of an allograft might be expected or might even be taking place.

The data presented in this paper are consistent with both these hypotheses, and we suggest that this type of rosette inhibition test forms a theoretically interesting and clinically useful system.

\section{Method of Preparing Rosettes}

The method was based on that described by Bach and Antoine (1968). The lymphocytes were obtained by filtering $5-7 \mathrm{ml}$ of freshly-drawn citrated blood (10\% trisodium citrate, $1 \mathrm{ml}$ to $9 \mathrm{ml}$ of blood) through a column of nylon wool (Rogier Bellon, Paris) and sedimented by adding 5\% dextran (Poviet Production, N.V., Amsterdam) to a final concentration of $1 \%$. The mixture was allowed to stand for 45 minutes at $37^{\circ} \mathrm{C}$ before being centrifuged at an angle of 45 degrees for 10 minutes at 1,000 r.p.m. $(160 \mathrm{~g})$ and the supernatant discarded.

The residue, which contained the cells, was washed twice in isotonic saline, resuspended in $1 \mathrm{ml}$ of saline, and shaken gently with $3 \mathrm{ml}$ of distilled water for 20 seconds to haemolyse the red cells. The remaining cells were washed again in saline and finally resuspended in Hanks's B.S.S. solution (calciumfree). The final solution was then adjusted with the Hanks's solution to contain $5 \times 106$ cells $/ \mathrm{ml}$.

Guinea-pig serum was prepared by absorbing any spontaneous rosette-inducing activity with equal volumes of washed human and sheep red blood cells. The sheep red blood cells were obtained from defibrinated blood and stored without a preservative. A fresh sample was prepared each week by the Burroughs Wellcome Research Laboratories, Beckenham. The human red cells were prepared from weekly samples of blood which were allowed to sediment and the supernatant was removed. These were then washed several times in isotonic saline. After absorption the red cells were spun off and the supernatant was diluted with five volumes of the Hanks's solution. This serum was prepared weekly and stored at $4^{\circ} \mathrm{C}$.

Altogether $0.05 \mathrm{ml}$ of the absorbed guinea-pig serum and $0.1 \mathrm{ml}$ of the prepared lymphocyte solution were added to $0.25 \mathrm{ml}$ of serial dilutions of A.L.G. (titres $1 / 4,000$ to $1 / 256,000$ ). A control in which Hanks's solution was used in place of the A.L.G. was also set up. The A.L.G. was antihuman A.L.G. prepared by Burroughs Wellcome against thoracic duct lymphocytes. A standard preparation is now available.

The suspensions were then incubated at $37^{\circ} \mathrm{C}$ for 90 minutes; $0.1 \mathrm{ml}$ of the sheep red blood cells (diluted $\times 30$ with saline), similar to those used in preparing the guinea-pig serum, were then added to each tube and centrifuged at 1,000 r.p.m. for five minutes, followed by resuspension on a rotary disc at 10 r.p.m. for 10 minutes. Before counting, a drop of $1 \%$ aqueous methylene blue was sometimes added to aid identification of rosettes (Fig. 1).

The number of rosettes were counted per 1,000 lymphocytes on a Fuchs-Rosenthal haemocytometer with $a \times 40$ lens for the lymphocytes and $a \times 20$ for the rosettes. The result was expressed as the number of rosettes per 1,000 lymphocytes as a percentage of the control (see Table).

Percentage inhibition $=$

No. of rosettes/1,000 lymphocytes in A.L.G. titres $\times 100$ No. of rosettes $/ 1,000$ lymphocytes in controls 


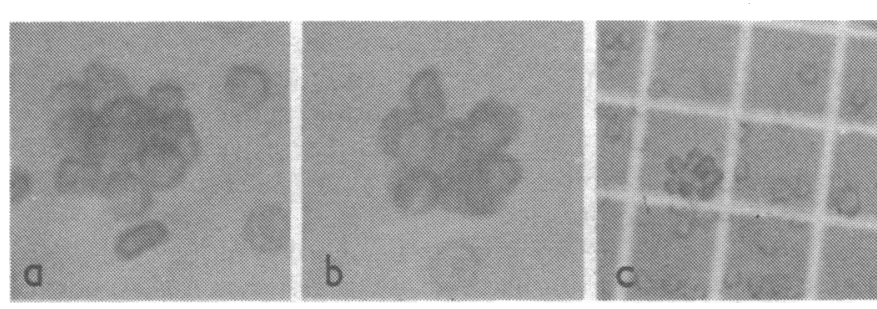

FIG. 1-A, B, Typical rosettes showing central nucleated cell surrounded by adherent sheep red blood cells. C, Rosette on the Fuchs-Rosenthal counting chamber showing approximate size.

Examples of Three Tests performed on Consecutive Days after Renal Transplantation. Patient started Immunosuppression with Azathioprine on Day 0

\begin{tabular}{|c|c|c|c|c|c|c|c|c|c|c|c|c|}
\hline \multirow[t]{2}{*}{$\begin{array}{l}\text { Dilution } \\
\text { of } \\
\text { A.L.G. }\end{array}$} & \multicolumn{3}{|c|}{ Rosettes } & \multicolumn{3}{|c|}{ Lymphocytes } & \multicolumn{3}{|c|}{$\begin{array}{c}\text { No. of Rosettes/ } \\
1,000 \\
\text { Lymphocytes }\end{array}$} & \multicolumn{3}{|c|}{$\begin{array}{l}\% \text { Rosette For- } \\
\text { mation/ 1,000 } \\
\text { Lymphocytes }\end{array}$} \\
\hline & I & II & III & $\mathbf{I}$ & II & III & I & II & III & I & II & III \\
\hline $\begin{array}{l}\text { Control } \ldots \\
1 / 4,000 \ldots \\
1 / 8,000 \ldots \\
1 / 16,000 \\
1 / 32,000 \\
1 / 64,000 \\
1 / 128,000 \\
1 / 256,000\end{array}$ & $\begin{array}{r}19 \\
6 \\
9 \\
10 \\
10 \\
12 \\
17 \\
18\end{array}$ & $\begin{array}{r}14 \\
6 \\
8 \\
10 \\
17 \\
13 \\
15 \\
21\end{array}$ & $\begin{array}{r}21 \\
6 \\
5 \\
9 \\
11 \\
18 \\
21 \\
24\end{array}$ & $\begin{array}{l}30 \\
24 \\
32 \\
11 \\
24 \\
12 \\
17 \\
18\end{array}$ & $\begin{array}{l}10 \\
12 \\
16 \\
15 \\
13 \\
16 \\
11 \\
11\end{array}$ & $\begin{array}{l}44 \\
94 \\
68 \\
58 \\
54 \\
72 \\
44 \\
48\end{array}$ & $\begin{array}{r}17 \\
6 \\
7 \\
9 \\
13 \\
16 \\
16 \\
17\end{array}$ & $\begin{array}{l}41 \\
14 \\
10 \\
14 \\
17 \\
21 \\
39 \\
41\end{array}$ & $\begin{array}{c}13 \\
1 \cdot 7 \\
2 \cdot 0 \\
3 \cdot 0 \\
4 \cdot 0 \\
6 \cdot 0 \\
10 \cdot 0 \\
13 \cdot 0\end{array}$ & $\begin{array}{r}100 \\
40 \\
41 \\
54 \\
80 \\
95 \\
98 \\
100\end{array}$ & $\begin{array}{r}100 \\
30 \\
25 \\
30 \\
40 \\
50 \\
98 \\
100\end{array}$ & $\begin{array}{c}100 \\
14 \\
15 \\
20 \\
30 \cdot 4 \\
46 \\
80 \cdot 0 \\
100\end{array}$ \\
\hline
\end{tabular}

The lymphocytes were usually counted over four of the smaller squares and the result was multiplied by $4 \times 9$ to give the total lymphocytes per counting area. If there was severe lymphopenia the area counted was increased. The rosettes were counted over the whole counting area. Examples of the number of rosettes and lymphocytes counted are given in the Table. The percentage inhibition was plotted against the A.L.G. titre, producing a sigmoid curve as shown in Fig. 2.

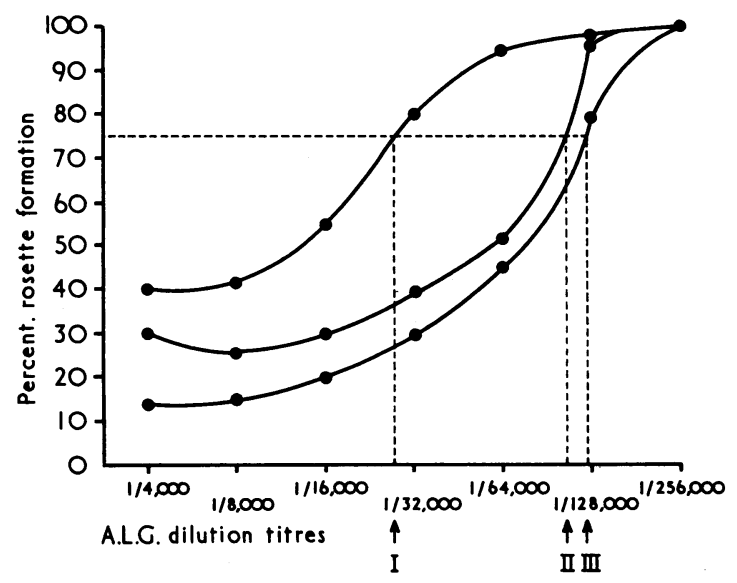

FIG. 2-Sigmoid curve and minimum inhibitory concentration titres of A.L.G. for the same patient. $I=$ First postoperative day, M.I.C. $1 / 25,000$. II $=$ Second postoperative day, M.I.C. $1 / 100,000$. III $=$ Third postoperative day, M.I.C. $1 / 125,000$.

From animal studies carried out by Bach and Brain it was postulated that the minimal inhibitory concentration (M.I.C.) was that dilution of A.L.G. inhibiting rosette formation by $75 \%$ of the control. Thus the result can be expressed as the M.I.C.; those in Fig. 2 would be $1 / 25,000,1 / 100,000$ and $1 / 128,000$ respectively. These figures should fall in the vertical part of the sigmoid curve-that is, where the percentage inhibition is rising rapidly with very little change in A.L.G. titre. We suggest that a shift in this curve to the right therefore indicates increased inhibition and thus increased immunosuppression.
The whole test takes less than four hours, and in skilled hands a result can often be obtained in three. Whole citrated blood can be stored for six to eight hours or separated cells at $4^{\circ} \mathrm{C}$ for 24 hours with very little change in the M.I.C. result.

Brain et al. (1970) used sequestrinated blood with similar results.

\section{PRECAUTIONS}

Bach et al. (1968) and B. Mosedale (personal communication, 1971) suggested that one of the important factors in obtaining reproducible results was to use carefully washed and rinsed glassware. Initially we washed our utensils in Chloros for $\mathbf{3 0}$ minutes and then in chromic acid for two hours before rinsing carefully in deionized water and drying. The Chloros was used to inactivate the hepatitis virus prevalent in our unit. Bach suggested that plastic tubes could be used, and more recently we have used disposable polystyrene tubes with plastic caps for convenience and to reduce the risks of hepatitis to the laboratory staff.

They also suggested that the most reproducible results were obtained with cells, A.L.G., and absorbed guinea-pig serum prepared at $4^{\circ} \mathrm{C}$. All equipment was stored at $4^{\circ} \mathrm{C}$ and the procedures were carried out quickly at room temperature (unless otherwise stated). Once the rosettes are formed no further temperature control is necessary, but the rosettes should be counted within 15 minutes. If this is not possible the rosettes should not be resuspended after centrifuging. The experiment can be halted for up to two hours at this stage if the tubes are stored at $4^{\circ} \mathrm{C}$. When required the rosettes can be resuspended (as above) and recounted.

The reproducibility of our individual results is shown in Fig. 3. Three technicians with varying experience in handling the test were each presented with samples of citrated blood taken from various subjects thought to have M.I.C.s across the range of the A.L.G. titres we used. The technicians did not know until the end of the test which sample came from which patient or what the A.L.G. titres were likely to be.

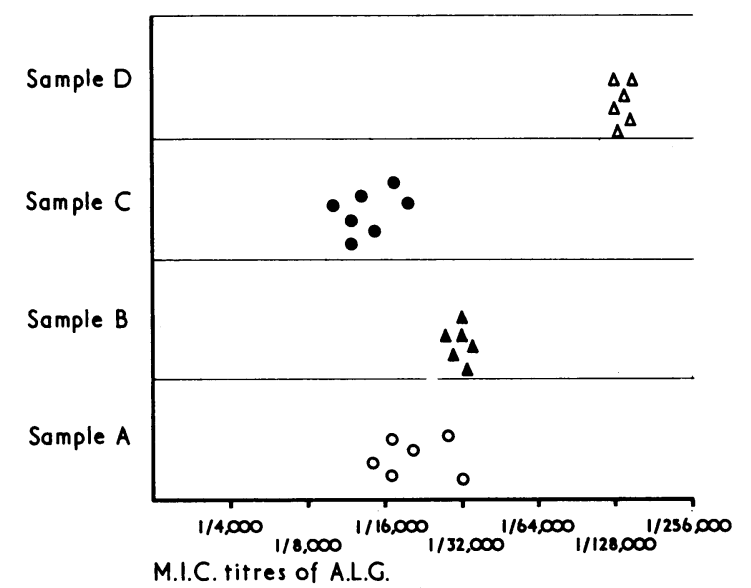

FIG. 3-Reproducibility of results using four samples of blood and three technicians. A, $=$ Normal patients. $B=$ Patient with chronic renal failure. $\mathrm{D}=$ Patient on immunosuppressive drugs-that is, well suppressed.

\section{Subjects}

Tests were carried out on five groups of patients.

Group 1.-Twenty-five normal subjects.

Group 2.-Fifteen patients ( 31 results) on regular haemodialysis with an average predialysis blood urea of $180 \mathrm{mg} / 100 \mathrm{ml}$ and a postdialysis urea of $50 \mathrm{mg} / 100 \mathrm{ml}$. All samples were taken before dialysis as heparin interferes with the rosette formation. 
Group 3.-Twenty-three patients (40 results) with renal allografts within the first six months of transplantation with good or improving renal function-that is, no clinical evidence of rejection.

Group 4.-Twenty-three patients (32 results) who had received a renal allograft more than 18 months previously and had stable renal function; none had had a change in their immunosuppressive therapy during the previous year.

Group 5.- Nineteen patients (21 separate rejection episodes) during the first 24 hours of a clinical rejection episode-the episodes were diagnosed on the usual criteria of increasing proteinuria, blood urea, and serum creatinine, with a fall in urinary output and creatinine clearance.

\section{Results}

The results are shown in Fig. 4. In the 25 normal subjects (group 1) the range of M.I.C.s was $1 / 16,000$ to $1 / 32,000$, while in 32 tests carried out on 23 patients with long-term successful renal allografts (group 4) the average titre was $1 / 112,000$ (range $1 / 96,000$ to $1 / 218,000$ ). Results from 23 patients with renal allografts in the first six months (group 3 ) showed a wide range of M.I.C. titres. The majority had titres at $1 / 64,000$ or above (average M.I.C. 1/96,000). The eight results at 1/16,000$1 / 32,000$ were from three patients. One developed a urinary fistula five days after receiving an "identical" matched allograft (Batchelor and Bristol plates). Clinically no rejection was observed. This may represent the relatively small stimulation to the immune system by a well-matched allograft at this early stage, though it is of note that his renal function did not improve until after the M.I.C. titre was greater than $1 / 64,000$.

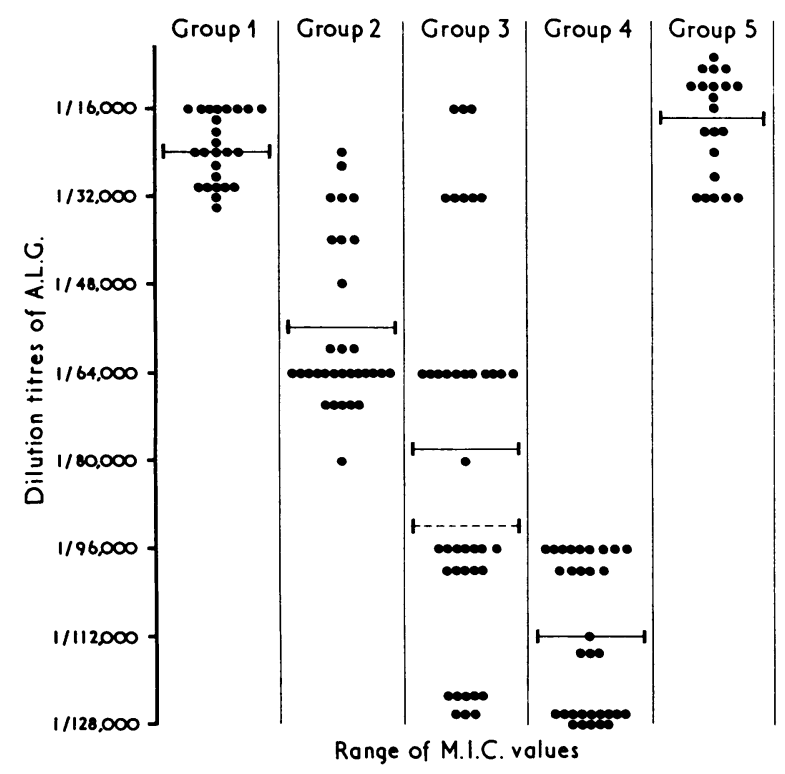

FIG. 4-Range of M.I.C. dilution titres for five groups of patients. In group 3 the mean overall value is shown as a solid line. The mean value including the eight readings of the normal range is shown as a broken line.

The other two patients had improving renal function at the time of the test but within one week and without further rosette tests had clinical rejection.

The 21 results recorded in group 5 were from 19 patients showing clinical signs of rejection. The tests were carried out on samples of blood taken before antirejection treatment was started. In only two episodes did a second sample, taken at 12 hours after the beginning of the treatment, show a lack of inhibition. In both these cases the rejection was not reversed and necessitated the patient returning to the dialysis programme.
In none of the rejection episodes that were successfully treated was the dilution of A.L.G. less than $1 / 64,00012$ hours after starting the treatment. It is interesting to note that though most of the M.I.C.s were in the normal range a few showed dilution less than this, suggesting that these lymphocytes were even harder to inhibit or suppress than those in patients on routine immunosuppression.

In the 15 patients on regular haemodialysis (group 2) the results showed that most had dilution titres greater than normal though less than those on routine immunosuppression (groups 3 and 4).

\section{Discussion}

Bach, Dardenne, and Fournier (1969a) found that in only $30-40 \%$ of their normal subjects could they obtain spontaneous rosette formation. In our experience we have not yet found a person who does not form some rosettes spontaneously. This has been confirmed by B. Mosedale (personal communication, 1971). Brain et al. (1970) showed that if the lymphocytes were washed thoroughly the postulated surface substance might be removed from the cells. This may be the reason for failure to form rosettes in some instances.

The identification and specificity of the rosette-forming cells have been discussed by Bach et al. (1968), Brain et al. (1970), and Bach and Dormont (1971). Bach and Dormont (1971) reviewed the convincing evidence that the cells involved in their mouse system were dreived from $\mathrm{T}$ lymphocytes. In man much less data are available, but the spontaneous rosette rate (rosette/ 1,000 lymphocytic cells) is much higher than in the mouse. Our own preparations stained with methylene blue show two types of cells which can easily be distinguished-small lymphocytes and larger cells with diffuse foamy nuclei, which we term "macrophages" (Fig. 1). Electron microscopical studies of rosette-forming cells in the mouse (Reyes and Bach, 1970) suggest that at least these two types of cell are involved in forming rosettes. In man it is possible that other cell types may be involved, and the method of preparing the cells from the peripheral blood will influence this.

If would be of great interest to investigate the nature of the rosette-forming cells in human peripheral blood. Nevertheless, our ignorance of the exact type or types of cell involved and of the specificity and significance of them does not detract from the practical value of the test at present described.

In those patients on haemodialysis the results showed at least partial inhibition of spontaneous rosette formation in most cases. There is other evidence of impairment of cellular immunity associated with uraemia. Prolonged skin graft survival has been reported by Smiddy, Burwell, and Parsons (1961) and by Dammin, Cough, and Murray (1957). Uraemic patients also had fewer positive intradermal skin tests of the delayed hypersensitivity type to various antigens than their related controls, according to Kirkpatrick, Wilson, and Talmage (1964). The response of lymphocytes to phytohaemagglutinin was reported as normal by Kasakura and Lowenstein (1967) and abnormal by Elves, Israels, and Collinge (1966). Folb (1970) noted normal lymphocyte transformation in patients on regular haemodialysis in our unit using Candida as the antigen.

\section{CLINICAL USE}

Initially our immunosuppression of patients with renal allografts was on conventional lines, with azathioprine and prednisone. Rejection episodes were diagnosed on the overall clinical picture. The prednisone dosage in our unit was $200 \mathrm{mg} /$ day for the first three days after transplantation and then $100 \mathrm{mg} /$ day, reducing slowly to $10 \mathrm{mg} /$ day at three months. Surveying the early rosette inhibition results retrospectively we were able to 
postulate that all patients with dilution titres less than $1 / 64,000$ were capable of rejection. Now the prednisone dosage can be reduced quickly, but even in the absence of clinical or laboratory criteria consecutive test results between $1 / 64,000$ and $1 / 50,000$ are treated by increasing the prednisone dosage by $20-30 \mathrm{mg}$ daily until the M.I.C. is greater than $1 / 64,000$. The immunosuppressive therapy can then after a few days be reduced slowly, the rosette inhibition being carefully watched. Test results less than $1 / 50,000$ in the absence of clinical signs are treated with $100 \mathrm{mg}$ of prednisone for three days, thereafter reducing the dosage. Full conventional antirejection treatment is given if clinical signs are present.

Care has to be taken in assessing single results. Technical errors can to a large extent be eliminated by using the percentage inhibition results from a true sigmoid curve. Where there have been wide changes in immunosuppressive therapy or in the M.I.C. titres over a short period to time the test should be repeated. Falling M.I.C. titres with constant immunosuppression, even when above $1 / 64,000$, should also be watched carefully.

The plasma creatinine, creatinine clearance, M.I.C. titres, and the immunosuppressive therapy in a girl who received a renal allograft six months previously are shown in Fig. 5. It shows how the prednisone dosage can be reduced to low levels rapidly and safely and still maintain improving renal function. It also shows that the test can be used to reduce the immunosuppressive therapy safely in the anuric period without the fear that a rejection episode is being missed in the absence of the usual clinical criteria.
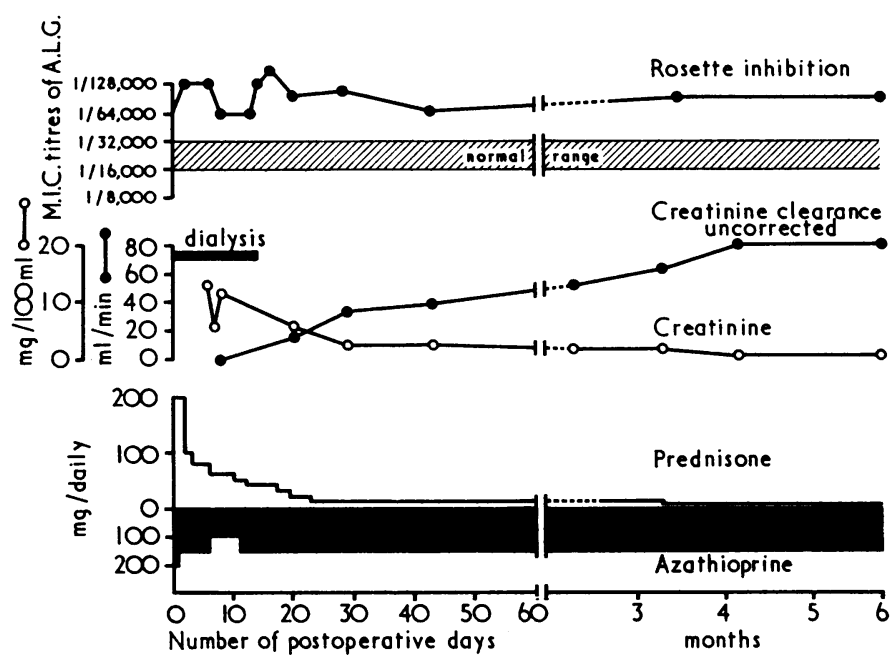

FIG. 5-Clinical criteria of renal function and M.I.C. dilution titres together with immunosuppressive regimen on a patient who received a renal allograft in May 1970.

Similar clinical criteria and two rejection episodes at about the 40th and 115th days after transplantation are shown in Fig. 6. It is of note that the downward trend of the rosette inhibition preceded the clinical picture.

One problem in which the test was of particular use was in the diagnosis of rejection in the presence of equivocal clinical signs, when the differential diagnosis included chest or urinary tract infection or technical problems such as ureteric obstruction or urinary fistula. At no time in evaluating 21 clinical rejection episodes (confirmed by the subsequent clinical course) have we had a rejection with a dilution titre of A.L.G. greater than $1 / 50,000$. As the test takes less than four hours to do we can await its result before beginning the appropriate treatment.

Thus we feel that the rosette inhibition test is a useful adjunct to the management of renal allografts when immunosuppression is achieved by azathioprine and steroids, at least in the first six months postoperatively. More recent work has shown it to be

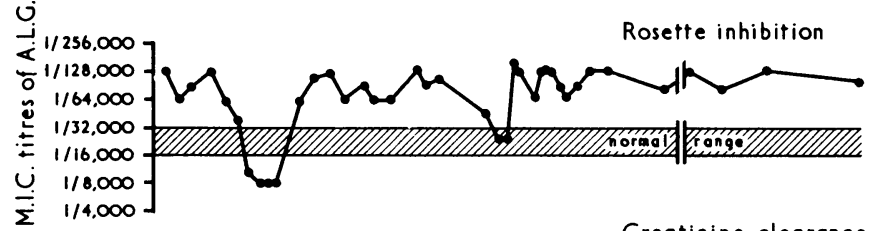

equally effective in immunosuppressive regimens in which A.L.G. is used.

Further work is being done to assess its efficacy in other organ transplants and other diseases requiring immunosuppression, such as ulcerative colitis, Crohn's disease, dermatomyositis, and the nephrotic syndrome. It is hoped to compare the results with other tests of lymphocyte function, such as lymphocyte transformation, macrophage migration, macrophage inhibition factor, serum immunoglobulin levels, and skin test sensitivity of the delayed type.

\section{References}

Awad, W., Bennett, L. R., and Martin, D. C. (1968). Fournal of Urology, 100, 233.

Bach, J. F., and Antoine, B. Nature, 217, 658

Bach, J. F., Dardenne, M., and Antoine, B. (1968). Pathologia et Biologia, $16,657$.

Bach, J. F., and Dormont, J. (1971). Transplantation, 11, 96.

Bach, J. F., Dardenne, M., and Fournier, C. (1969a). Nature, 222, 998.

Bach, J. F., Dormont, J., Dardenne, M., and Balner, H. (1969b). Transplantation, 8, 265.

Bach, J. F., Dormont, J., Dardenne, M., and Balner, H. (1970). Pharmacological Treatment in Organ and Tissue Transplantations: Proceedings of International Symposium, Milan, 1970, ed. A. Bertelli and A. P. Monaco. Amsterdam, Excerpta Medica Foundation.

Biozzi, G., et al. (1966). Annales de l'Institut Pasteur, 110, Suppl. No. 7, p. 32 Birsner, J. W., Gershon-Cohen, J., and Gainey, M. D. (1971). Transplantation, 11, 424.

Brain, P., and Gordon, A. J. (1970). South African Medical fournal, 44, 784.

Brain, P., Gordon, J., and Willetts, W. A. (1970). Clinical and Experimenta Immunology, 6, 681 .

Chisholm, G. D., Papadimitriou, M., Kukatilake, A. E., and Shackman, R. (1969). Lancet, 1, 904.

Dammin, G. J., Cough, N. P., and Murray, J. E. (1957). Annals of the New York Academy of Sciences, 64, 967.

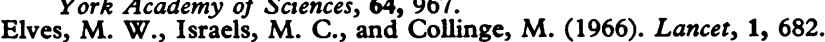

Folb, P. I. (1970). M.D. thesis (Cape Town)

Hume, D. M., Magee, J. H., Kauffman, H. M., Rittenburg, M. S., and Prout, G. R. (1963). Annals of Surgery, 158, 608.

Kasakura, S., and Lowenstein, L. (1967). Transplantation, 5, 283.

Kincaid-Smith, P. (1967). Lancet, 2, 849.

Kincaid-Smith, P., Morris, P. J., Saker, B. M., Ting, A., and Marshall, V. C. (1968). Lancet, 2, 748.

Kirkpatrick, C. H., Wilson, W. E., and Talmage, D. W. (1964). Fournal of Experimental Medicine, 119, 727.

Kountz, S. L., Laub, D. R., and Cohn, R. (1965). Fournal of the American Medical Association, 191, 997.

Millard, P. R., Herbertson, B. M., and Evans, D. B. (1970). Lancet, 1, 113.

Mookerjee, B., Gault, M. H., and Dossetor, J. B. (1969). Annals of Internal Medicine, 71, 47. 
Parker, J. (1969). Ph.D. thesis (London).

Parker, J., Ellis, F. G., Cameron, J. S., and Ogg, C. S. (1970). Proceedings of the European Dialysis and Transplant Association, 7, 331.

Parker, J. R., and Mowbray, J. F. (1971). Transplantation, 11, 201

Rapoport, A., and Husdan, H. (1968). Canadian Medical Association fournal, $99,149$.

Russel, P. S., and Monaco, A. P. (1964). New England fournal of Medicine, 271,502 .

Salaman, J. R. (1970). British Medical fournal, 2, 517.
Salerni, B., et al. (1970). In Proceedings of 5th Congress of European Society

for Experimental Surgery, p. 108.
Sampson, D. (1969). Lancet, 2, 976.

Smiddy, F. G., Burwell, R. G., and Parsons, F. M. (1961). Nature, 190, 732

Smiddy, F. G., Burwell, R. G., and Parsons, F. M. (1961). Nature, 190, 732

Storb, U., and Weiser, R. S. (1966). Fournal of the Reticuloendothelial Society, 4,51 .

Tennenbaum, J. I., St. Pierre, R. L., and Cerilli, G. J. (1968). Transplantation, 6, 986.

\title{
Prostaglandin $\mathrm{E}_{2}$ Compared with Oxytocin for the Induction of Labour
}

\author{
I. L. CRAFT, \\ A. R. CULLUM, \\ D. T. L MAY, \\ A. D. NOBLE, \\ D. J. THOMAS
}

British Medical fournal, 1971, 3, 276-279

\begin{abstract}
Summary
A comparison has been made between the effectiveness of infusing prostaglandin $E_{2}$ with Syntocinon for the induction of labour in the presence of intact membranes. Rapid titration schedules were used to induce an early uterine response. All 15 subjects receiving prostaglandin $E_{\text {, }}$ achieved cervical dilatation, whereas this occurred in only 9 out of 15 patients receiving Syntocinon.
\end{abstract}

\section{Introduction}

The intravenous infusion of oxytocin is now widely accepted as an effective and safe method of inducing labour even when administered on a rapid titration basis. Recently it has been reported that the infusion of prostaglandin $E_{2}$ is also effective in inducing labour (Beazley et al., 1970; Embrey, 1970; Karim et al., 1970). Karim et al. (1970) succeeded in inducing labour in each of 50 patients by using a continuous infusion of $0.5 \mu \mathrm{g} / \mathrm{min}$. Embrey (1970), who used doses of 0.5-6.0 $\mu \mathrm{g} / \mathrm{min}$, had two failures in a series of 25 inductions. In some women oxytocin administration may fail to induce labour, especially when the membranes remain intact. This fact prompted us to compare the effectiveness of prostaglandin $\mathrm{E}_{2}$ with that of the synthetic oxytocin, Syntocinon, in inducing labour.

\section{Patients and Methods}

The patients who participated in this study required induction at or near term for various reasons. They were selected at random into two groups according to whether their case record ended in an odd or an even number, one group receiving oxytocin and the other prostaglandin $\mathrm{E}_{2}$. Those with a multiple pregnancy, an abnormal presentation, suspected cephalopelvic disproportion or a height under $5 \mathrm{ft} 1$ in $(155 \mathrm{~cm})$, or a previous operation on the cervix were excluded. The agents were admini-

\footnotetext{
Departments of Obstetrics and Gynaecology, Queen Mary's Hospital, London S.W.15, and Westminster Hospital, London S.W.1

I. L. CRAFT, F.R.C.S., M.R.C.O.G., Senior Registrar

A. R. CULLUM, F.F.A. R.C.S., Senior Registrar

A. R. CULL T. L. MAY, F.R.C.S.ED., M.R.C.O.G., Registrar
D. T.

D. T. L. MAY, F.R.C.S.ED., M.R.C.O.G., Registrar

D. J. THOMAS, F.R.C.S.ED., M.R.C.o.G., Registrar
}

stered by a slow infusion pump (Scientifica and Cook) on a titration basis according to the schedules described below in the presence of intact membranes.

The infusion rates were adjusted so that contractions occurred optimally every two to three minutes and lasted $40-50$ seconds, and the infusion was maintained until delivery in each instance. Uterine contractions and fetal heart recordings were monitored continuously throughout labour with a Hewlett Packard cardiotocograph. Baseline recordings were obtained for at least 15 minutes before the start of infusion. During the induction of labour the membranes were ruptured artificially only in those cases of suspected fetal distress, as determined by fetal heart variations of more than 30 minutes' duration. In these subjects fetal blood samples were taken and they were subsequently eliminated from the final analysis. This was made on 30 patients, 15 in each group.

The essential criterion chosen to indicate successful induction was dilatation of the cervix. Since both primigravid and multigravid patients were studied it was decided to regard an increase in dilatation over that present before the onset of infusion as evidence of success rather than cervical dilatation of a certain arbitrary degree. Failure was considered to have occurred if there was no change over a 12-hour period. In this event the infusion was stopped, the patient was allowed to rest for the night, and other plans were made to effect delivery the next day. If progress had occurred infusions were kept running until delivery, maintaining contractions at the optimum rate and duration. Vaginal examinations were performed every four hours by one observer in each case. The degree of cervical dilatation was noted on each occasion though consideration was not given to changes in the length of the cervical canal.

Before the infusion was started each subject had an epidural catheter inserted. Bupivacaine $0.5 \%$ was later given at intervals as required, ensuring a standard method of analgesia and facilitating accurate recording of contractions and fetal heart rate by the external cardiotocograph. The times of alteration in the infusion rate were recorded, ensuring knowledge of the total quantity of each agent used. The times of onset of spontaneous membrane rupture and full dilatation were noted, as was the presence of any maternal cardiovascular or gastrointestinal side effects. Fetal well-being was assessed by Apgar scores taken at one and five minutes. At the conclusion of the study an attempt was made to correlate the Apgar score and the occurrence of type 2 decelerations in fetal heart rate recorded on the cardiotocograph with the agent used.

\section{TITRATION SCHEDULES}

Oxytocin.-The regimen used was that described by Turnbull and Anderson (1968). The infusion was started at $1 \mathrm{mU} / \mathrm{min}$, the rate being doubled every 10 minutes until contractions 